\title{
Tercih Maddesi Ve Bağımlılık Şiddetine Bakılarak Bağımlılarda Yaşama Son Verme Düşüncesi Yoğunluğunun Araştırılması
}

\author{
Nur KASSEM ${ }^{1}$
}

\begin{abstract}
Özet: Yaşı 21 ve 65 arasında değişen 525 (Erkek: 497, Kadın: 28) alkol ve madde bağımlısı katılımcının bağımlılık düzeyleri ile yoğun intihar düşünceleri arasındaki ilişki araştırılmıştır. Elde edilen veriler Türkiye'de bir ayaktan bağımlılıkta psikolojik ve sosyal destek merkezinden alınmıştır. İntihar düşüncesinin yoğunluğu, bağımlılık şiddeti ölçümü Bapi (Ögel ve Ark., 2012) ölçeğinden elde edilen sonuçlara göre düzenlenmiştir. Elde edilen bulgulara göre, Sentetik kannabinoid bağımlılarının \%9'u yoğun olarak intihar düşüncelerine sahiptir. Çalışmada eroin bağımlısı katılımcıların \%28'inin yoğun olarak intihar düşüncesine sahip olduğu görülmüştür. Yüksek şiddette esrar bağımlılarına nazaran orta şiddette esrar bağımlılarının yoğun intihar düşüncelerine sahip olduğu ortaya çıkmıştır. Yüksek şiddette alkol ve ecstasy bağımlılarının yarısının neredeyse her zaman yaşamına son verme düşünesine sahip olduğu görülmüştür. Elde edilen sonuçlar genel olarak madde ve alkol bağımlılı̆ıının intihar düşüncesini arttırdığını göstermektedir.
\end{abstract}

Anahtar Kelimeler: Bağımlılık şiddeti, İntihar, psikolojik destek, yaşama son verme

\section{A Research on the Intensity of Suicidal Thoughts, Regarding the Relation Between Drugs of Choice and Levels of Addiction Among Addicted Populations}

\begin{abstract}
The relation between levels of addiction and intensity of suicidal thoughts in 525 clients who are between ages of 18 and 65 (male: 497, female: 28) have been studied in a drug and alcohol addiction outpatient clinique. For measuring both the intensity of suicidal thoughts and levels of addiction, a specific tool called BAPI was used in this study. The results show that among synthetic cannabinoid users $9 \%$ have very intense suicidal thoughts. Study results showed that among heroine users, $28 \%$ have very intense suicidal thoughts. Interestingly, among cannabis users, moderately addicted ones have been found to have more intense suicidal thoughts than the ones who are highly addicted. Among alcohol and MDMA users half of the clients have reported to have intense suicidal thoughts. Results indicate that heroine, alcohol and cannabis along with MDMA addiction might cause one to have depression and intense suicidal thoughts. Further studies are needed.
\end{abstract}

Keywords: drug addiction, intense suicidal thoughts, alcohol addiction

${ }^{1}$ Uzm. Psk., Yeşilay Danışmanlık Merkezi, Cerrahpaşa YEDAM

Address of correspondence/ Yazışma adresi: Uzm. Psk. Nur Kassem, Yeşilay Danışmanlık Merkezi, Cerrahpaşa YEDAM, E-mail: nur.kassem@yesilay.org.tr

Date of Received/Geliş Tarihi: 26.10.2019, Date of Revision/Düzeltme Tarihi: 02.11 .2019 , Date of Acceptance/Kabul Tarihi: 05.11.2019

Citing/ Referans Gösterimi: Kassem, N. (2019). A Research On The Intensıty Of Suıcıdal Thoughts, Regardıng The Relatıon Between Drugs Of Choıce And Levels Of Addıctıon Among Addıcted Populatıons. Kıbrls Türk Psikiyatri ve Psikoloji Dergisi, 1(Özel Sayı.1): 36-39 doi:10.35365/ctjpp.19.special1.10 


\section{Giriş}

Ülkemizde uyuşturucu madde bağımlılığı son 5 yılda gözle görülür bir artış göstermiştir. 2017 Türkiye Uyuşturucu raporunda belirtilen verilere göre ülkemizde en fazla uyuşturucu madde kullanım bozukluğuna, uyuşturucu madde bağımlılığına, sahip kişiler 25-29 yaş aralığındaki kişilerdir. $\mathrm{Bu}$ yaş grubundan bağımlıların çeşitli ruhsal sorunlara sahip olduğu bilinmektedir. Bu ruhsal sorunlar arasında dürtüsellik, kaygı bozukluğu, majör depresyon, depresyona bağlı intihar düşüncelerinin oluşması, halüsinasyon ve hezeyanların oluşması bulunmaktadır.

Yapılan bu çalışmalar 1şığında bu çalışmada Türkiye'de bir alkol ve uyuşturucu bağımlılığg ayaktan tedavi merkezinden destek alan katılımcıların verilerine bakılarak son bir yıl içinde en yoğun kullandıkları uyuşturucu madde, bağımlılık şiddetleri ve intihar düşüncelerinin yoğunluğu arasındaki ilişkinin araştırılması amaçlanmıştır.

\section{Yöntem}

Yapılan çalışmanın örneklemi İstanbul'da bulunan Yeşilay Danışmanlık Merkezi adlı alkol ve uyuşturucu bağımlılığı ayaktan psikolojik ve sosyal destek merkezinin klinik ilk görüşme verilerinden elde edilmiştir. 16-65 yaş aralığında 525 bağımlı (erkek:497, kadın: 28) yer almaktadır. Tercih maddeleri, kullanıcı sayısı ve kullanıcı yüzdeleri aşağıda verilmiştir.(Tablo:1)İntihar düşüncesi yoğunluğunu ölçmek için verilerin alındığı merkezin kullandığ 1 katılımeının ruhsal durumunu analiz etmek amaciyla kullanılan 'Bapisoft' adlı bir ölçek kullanılmıştır. Katılımcılar tarafindan bu sorulara verilen yanıtların ortalaması alınmış ve katılımcılar bağımlılık şiddetlerine göre 'orta' ve 'yüksek' olmak üzere 2 gruba ayrılmıştır. Bu çalışmada gruplara göre elde edilen sonuçlar çift örneklem t-testi analizinden geçirilmiş ve bağımlılık şiddeti ile intihar düşüncesi yoğun olan kişi sayısı karşılaştırılmıştır.

\section{Bulgular}

\begin{tabular}{|ccc|}
\hline TERCIH MADDESI & K. SAYISI & DAĞILIM (\%) \\
SENTETIK KANNABINOID & 213 & $\% 40.5$ \\
EROIN & 96 & $\% 18.3$ \\
ESRAR & 72 & $\% 13.7$ \\
ALKOL & 77 & $\% 14.7$ \\
ECSTASY & 19 & $\% 3.6$ \\
KOKAIN & 14 & $\% 2.6$ \\
TAŞ & 10 & $\% 1.9$ \\
UÇUCU & 4 & $\% 0.7$ \\
METH & 3 & $\% 0.6$
\end{tabular}

Tablo 1: Tabloda katılımcıların tercih maddelerine göre dağılımları gösterilmiştir.

\begin{tabular}{|ccc|}
\hline TERCIH MADDESI & Y. Ş. BAĞIMLI SAYISI & O. Ş. BAĞIMLI SAYISI \\
BONZAi & 213 & 0 \\
EROIN & 90 & 6 \\
ESRAR & 40 & 32 \\
ALKOL & 58 & 21 \\
ECSTASY & 10 & 9 \\
KOKAIN & 13 & 1 \\
TAŞ & 10 & 0 \\
UÇUCU & 4 & 1 \\
METH & 3 & 0 \\
Tablo 2 & &
\end{tabular}

Sentetik kannabinoid bağımlıları bu çalıșmada 213 (\%45) katılımcı ile en büyük çoğunluğu oluşturmaktadır. Kullanıcılardan yüksek şiddette bağımlı olanların yarısının, neredeyse her zaman yaşamına son verme düşüncesine sahip olduğu ortaya çıkmıştır. $\mathrm{Bu}$ çalışmada orta şiddette sentetik kannabinoid bağımlısı bulunmamaktadır. Eroin kullanıcılarından yüksek şiddette bağımlı olanların \%39'u, orta şiddette bağımlı olan 9 katılımcının tamamının neredeyse her zaman intihar düşüncesine sahip olduğu ortaya çıkmıştır. Esrar kullanıcılarından yüksek şiddette bağımlı olanların 4/5'inin neredeyse her zaman yaşamına son verme düşüncelerine sahip olduğu, orta şiddette olan esrar bağımlılarının \%34'ünün neredeyse her zaman yaşamına son verme düşüncesine sahip olduğu ortaya çıkmıştır. Alkol kullanıcılarından yüksek şiddette bağımlı grubuna bakıldığında katılımcı grubunun yarısının neredeyse her zaman yaşamına son verme düşüncesinin olduğu, orta şiddette alkol bağımlılarının \% 23ünün neredeyse her zaman yaşamına son verme düşüncesinin olduğu gözlemlenmiş̧ir. Ecstasy kullanıcılarından yüksek şiddette bağımlı olanların \%30'unun, orta şiddette bağımlı olanların \%16'sının neredeyse her zaman 
yaşamına son verme düşüncesinin olduğu gözlemlenmiştir. Ecstasy tercih maddesine göre yüksek ve orta şiddetli bağımlı grupları arasında intihar düşüncesi yoğunluğu açısından istatistiksel olarak anlamlı bir fark olmadığı ortaya çıkmıştır (p>0.05). Kokain kullanıcılarından yüksek şiddette bağımlı olanların yarısı her zaman yaşamına son verme düşüncesine sahiptir. Çalışmada orta şiddette bağımlı 1 katılımcı bulunmaktadır. Taş kullanıcılardan yüksek şiddette bağımlıların \%30'unun neredeyse her zaman yaşamına son verme düşüncesine sahip olduğu gözlemlenmiştir. $\mathrm{Bu}$ çalışmada taş kullanıcıları arasında orta şiddette bağımlı katılımcı bulunmamaktadır. Uçucu madde kullanıcılarından yüksek şiddette bağımlıların 3/4'ünün neredeyse her zaman yaşamına son verme düşüncesi olduğu gözlemlenmiştir. Çalışmada uçucu madde kullanan orta şiddette bağımlı bulunmamaktadır. Metamfetamin kullanıcılarının yüksek şiddette bağımlıların 1/3'ü neredeyse her zaman yaşamına son vermeyi düşünmektedir. Çalışmada metamfetamin kullanan orta şiddette bağımlı bulunmamaktadır.

\section{Tartıșma}

$\mathrm{Bu}$ çalışmada elde edilen bulgulara göre tercih maddesi sentetik kannabinoid olan katılımcıların tümü yüksek şiddette bağımlı grubuna girmektedir. Esrar kullanımı ile karşılaştırıldığında bağımlılık potansiyelinin çok daha yüksek olduğu ortaya çıkmıştır. Çalışmada yer alan 20 yüksek şiddette sentetik kannabinoid bağımlısının neredeyse her zaman yaşamına son verme düşüncesinin olduğu bulgusu sentetik kannabinoidlerin majör depresyonu tetikleyen bir etken olduğunu düşündürmektedir. Eroin bağımlısı 96 katılımeının 27'sinin yoğun intihar düşüncelerinin olduğu ortaya çıkmıştır. 27 bağımlının 6'sını kadın bağımlılar oluşturmaktadır. Toplamda 8 eroin bağımlısı katılımcının 6'sının neredeyse her zaman yaşamına son verme düşüncesinin olması eroin bağımlılığı ile majör depresyonun yakından ilişkili olduğunu göstermektedir. Bu çalışmada elde edilen sonuçlara göre orta şiddette bağımlı 8 katılımcının herbiri intihar düşüncesine sahiptir. Ancak yüksek şiddette bağımlı olan katılımcıların ancak \%39'u her zaman intihar düşüncesi olduğunu belirtmiştir. $\mathrm{Bu}$ çalışmada elde edilen bulgulara göre yüksek şiddette esrar bağımlısı grubun yoğun intihar düşüncesine sahip olduğu gözlenmiştir.

Alkol bağımlısı 77 katılımcıdan 27 orta şiddette alkol bağımlısından 5'inin neredeyse her zaman yaşamına son verme düşüncesi olduğu, 58 yüksek şiddette alkol bağımlısı katılımcının 31'inin neredeyse her zaman yaşamına son verme düşüncesinin olduğu çalışmada gösterilmiştir. Katılımcıların neredeyse yarısının intihar düşüncelerine sahip olduğu görülmüştür.
Bağımlı ve yoğun intihar düşüncesine sahip katılımcılar sayıca orta şiddette bağıml katılımcılardan fazladır. Ecstasy bağımlısı katılımcidan 9'u neredeyse her zaman intihar düşüncesine sahip olduğunu belirtmiştir. Geçmişte ecstasy kullanımı ile intihar düşüncesinin ilişkisini ölçen bir çalışmaya rastlanmamıştır. Ancak bu bulgudan yola çıkarak ecstasy maddesinin her iki kullanıcıdan birinde intihar düşüncesini tetiklediği söylenebilir. 14 kadın katılımcıdan 2'sinin yüksek şiddette bağımlı olduğu ve yoğun olarak yaşamına son verme düşüncesi olduğu görülmüştür. Bu bulgudan yola çıkılarak ecstasy bağımlılığının kadınlarda intihar düşüncesini etkileyen bir faktör olduğu söylenebilir. 14 Kokain bağımlısı katılımcıdan 13'ünün yüksek şiddette bağımlı olduğu görülmüştür. $\mathrm{Bu}$ bulgu kokainin bağımlılık potansiyelinin yüksek olduğunu göstermektedir. $\mathrm{Bu}$ bulgudan yola çıkarak her 100 kokain kullanıcısından 43'ünün yoğun intihar düşüncelerine sahip olduğu söylenebilir. Taş - krak kokain bağımlısı katılımcılar arasında bu çalışmada orta şiddette bağımlı bulunmamaktadır. Katılımcıların tümünün yüksek şiddette bağımlı olduğu görülmüştür. $\mathrm{Bu}$ bulgu krak kokainin yüksek bağımlılık potansiyeli olduğunu açıkça göstermektedir. Uçucu madde kullanımının hafızanın işlevini olumsuz etkilediği bilinmektedir. Uçucu madde kullanımı sonucu kardiyak aritmiye bağlı ani ölümler veya halusinatif düşüncelere bağlı ani ölümler olduğu bilinmektedir. (Boztaş ve Arısoy, 2010). Bu çalışmada elde edilen bulgulara bakıldığında uçucu madde bağımlısı 4 kişiden 3'ü yoğun intihar düşünceleri olduğunu belirtmiştir. $\mathrm{Bu}$ bulguya bakılarak uçucu madde bağımlılığının intihar düşüncelerini tetikleyici ve arttırıcı bir unsur olduğu söylenebilir. Metamfetamin kullanımının majör depresyon, paranoid düşüncelerin yoğunlaşması gibi birçok ağır ruhsal sorunlara yol açtığı bilinmektedir. Bağımlılık potansiyelinin yüksek olduğu bilinmektedir. Metamfetaminin intihar düşüncelerini arttırdığı ve tetiklediği söylenebilir. Sentetik kannabinoid kullanımı olan katılımcıların oldukça azının yoğun intihar düşüncelerinin olduğunu belirtmesi beklenmeyen bir sonuçtur.

İleride yapılacak çalışmalarda madde ve alkol bağımlılığı alanlarında örneklemin arttırılması, bağımlılık düzeyi ile yoğun intihar düşüncesi arasındaki ilişkiyi daha açı bir şekilde ortaya koyacaktır.

Alkol ve uyuşturucu bağımlısı bireylerin iyileşme süreçlerinde psikolojik destek ve sosyal hizmet desteği almasının süreçlerini hızlandırdığı ve iyileşmeyi sağlamlaştırdığı bilinmektedir. Bu çalışmada edinilen bulgular 1şı̆̆ında psikolojik desteğin devamı ve artması ile intihar düşüncesinin ortadan kalkabileceği düşünülmektedir.

\section{Kaynaklar}

Blair-West, G. W., Cantor, C. H., Mellsop, G. W., \& EyesonAnnan, M. L. (1999). Lifetime suicide risk in major depression: sex and age determinants. Journal of affective disorders, 55(2-3), 171-178.

Boztaş, M. H., Kaygusuz, Ç. Ç., Arısoy, Ö., \& Gürel, S. (2011). Chronic inhalant dependence with early onset cognitive impairment, depression and psychotic disorders: a case report. Dusunen Adam, 24(1), 69.

Dragisic, T., Dickov, A., Dickov, V., \& Mijatovic, V. (2015). Drug addiction as risk for suicide attempts. Materia sociomedica, 27(3), 188 . 
Du Roscoät, E., Legleye, S., Guignard, R., Husky, M., \& Beck, F. (2016). Risk factors for suicide attempts and hospitalizations in a sample of 39,542 French adolescents. Journal of affective disorders, 190, 517-521.

Evren, C., \& Bozkurt, M. (2013). Sentetik kannabinoidler: son yillarin krizi. Dusunen Adam, 26(1), 1.

Fernández-Montalvo, J., López-Goñi, J. J., Arteaga, A., \& Haro, B. (2019). Suicidal ideation and attempts among patients with lifetime physical and/or sexual abuse in treatment for substance use disorders. Addiction Research \& Theory, 27(3), 204-209.

Kannabinoidler, S. (2016). Ankara. Türkiye Uyuşturucu ve Uyuşturucu Bağımlılığı İzleme Merkezi.Klonsky, E. D., May, A. M., \& Saffer, B. Y. (2016). Suicide, suicide attempts, and suicidal ideation. Annual review of clinical psychology, 12, 307-330.

Oquendo, M. A., Ellis, S. P., Greenwald, S., Malone, K. M., Weissman, M. M., \& Mann, J. J. (2001). Ethnic and sex differences in suicide rates relative to major depression in the United States. American Journal of Psychiatry, 158(10), 1652-1658.

Pedersen, W. (2008). Does cannabis use lead to depression and suicidal behaviours? A population- based longitudinal study. Acta Psychiatrica Scandinavica, 118(5), 395-403.
Preuss, U. W., Schuckit, M. A., Smith, T. L., Danko, G. P., Buckman, K., Bierut, L., ... \& Reich, T. (2002). Comparison of 3190 alcohol- dependent individuals with and without suicide attempts. Alcoholism: Clinical and Experimental Research, 26(4), 471-477.

Rodríguez-Cintas, L., Daigre, C., Braquehais, M. D., PalmaAlvarez, R. F., Grau-López, L., Ros-Cucurull, E., ... \& Roncero, C. (2018). Factors associated with lifetime suicidal ideation and suicide attempts in outpatients with substance use disorders. Psychiatry research, 262, 440-445.

Ögel, K., Evren, C., Karadağ, F., \& Gürol, T. (2012). Bağımlılık Profil İndeksi'nin (BAPİ) geliştirilmesi, geçerlik ve güvenilirliği. Türk Psikiyatri Dergisi, 23(4), 264-273.

Twenge, J. M., Joiner, T. E., Rogers, M. L., \& Martin, G. N. (2018). Increases in depressive symptoms, suicide-related outcomes, and suicide rates among US adolescents after 2010 and links to increased new media screen time. Clinical Psychological Science, 6(1), 3-17.

Yuodelis- Flores, C., \& Ries, R. K. (2015). Addiction and suicide: a review. The American journal on addictions, 24(2), 98-104. 